\title{
Air temperature and death rates in Texas, 1968-2013
}

John Hart

Correspondence: jhartdc@yahoo.com

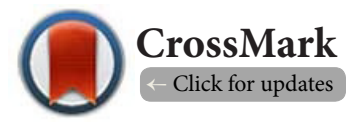

Hart Chiropractic, Greenville, SC, USA.

\begin{abstract}
Background: There is concern about harmful effects of "global warming", characterized as an approximate 1.5 degrees Fahrenheit increase in a global temperature over the last 130 years or so. The present study tests global warming theory on a local level, for Texas.

Methods: Using an ecological design, average daily maximum air temperature ("temperature") in Texas for 1968-2013 was compared to age-adjusted all-cause mortality ("deaths") in Texas for the same years using Pearson correlation $(\mathrm{n}=46$ years). The comparison was made for three race categories, where each category included all ages and both genders: white, black, and all races.

Results: There was 6.0 degrees Fahrenheit range for the years studied (74.9-80.9 degrees Fahrenheit). Correlations were moderate strength, inverse, and statistically significant, as follows. Whites: $r=-0.589$, $\mathrm{p}<0.0001$; Blacks: $\mathrm{r}=-0.619, \mathrm{p}<0.0001$; and all races: $\mathrm{r}=-0.597, \mathrm{p}<0.0001$.

Conclusions: These correlations show that as temperature increased over these years, death rates unexpectedly tended to decrease. A limitation to the study is its (ecological) design, but is an initial step for future research.
\end{abstract}

Keywords: Global warming, death rates, environmental epidemology, urbanization

\section{Introduction}

There is concern in recent years about "global warming", characterized as an approximate 1.5 degrees Fahrenheit increase in a "global temperature" in the last 130 years or so [1]. Dire predictions about death rates have been made. For example, one headline reads: "Global warming will cause rise in death rates" [2]. Another story claims that global warming "is already responsible for some 150,000 deaths each year around the world, and fear that the number may well double by 2030 even if we start getting serious about emissions reductions today" [3]. Similar predictions of doom and gloom can be found in the scholarly literature, where a "sizeable net increase in weather-related mortality is estimated if the climate warms as the models predict" [4]. Many of these dire predictions are based on educated guesses, known as modeling. However, these are still only guesses. Previous research that looked at existing data used a geographical design, where temperature and death rates by county were studied $[\mathbf{5 , 6}]$. These studies failed to show a trend of higher death rates in warmer counties. The present study tests global warming theory on a local level, for Texas, using a time-series design, comparing past average statewide temperatures to past death rates for matching years. In this way, actual evidence is generated as opposed to the educated guesswork involved with predictions based on modeling and the like.

\section{Methods}

Age-adjusted all-cause death rates per 100,000 for Texas were obtained for all available years from interactive databases through the Centers of Disease Control and Prevention [7]. These years included 1968-2013. The death rates included all ages and both genders. Three different race categories were selected: all races, blacks, and whites. The advantage of selecting Texas is its large size and population. The death rates were compared to average daily maximum temperatures in degrees Fahrenheit, obtained from the National Oceanic and Atmospheric Administration for the same years (1968-2013) [8].

Scatter plots revealed reasonable linear relationships between the temperatures and death rates (for the three race categories). Additionally, probability plots revealed reasonable normality of the data. Thus, Pearson correlation was considered appropriate for these data and was performed in Stata IC 12.1 (Stata Corp, College Station, TX). Two-tailed p-values less than or equal to the conventional alpha level of 0.05 were considered 
John Hart, Epidemiology Reports 2015,

statistically significant. The null hypothesis was no correlation between the two variables (temperature and death rates). The alternative hypothesis was a correlation exists between the variables (either direct or inverse).

\section{Results}

Descriptive statistics are provided in Table 1 while correlations are provided in Table 2. There was 6.0 degrees Fahrenheit range (74.9-80.9) where temperatures generally increased over the 46 year period (Figure $1 ; r=0.624, p<0.001$ ). However, all three race categories revealed moderate strength, inverse, statistically significant correlations as follows. All races: $r=-0.597$, $p<0.0001$; Blacks: $r=-0.619, p<0.0001$; and Whites: $r=-0.589$, $p<0.0001$ (Figures 2-4).

Table 1. Descriptive statistics. Mortality is age-adjusted per 100,000 . Temperature is in degrees Fahrenheit.

\begin{tabular}{llllll}
\hline Variable & n & Mean & SD & Minimum & Maximum \\
\hline All race mortality & 46 & 952.9 & 130.4 & 751.6 & 1250.5 \\
Black mortality & 46 & 1183.4 & 139.2 & 890.0 & 1458.0 \\
White mortality & 46 & 934.7 & 125.1 & 749.4 & 1226.1 \\
Temperature & 46 & 77.3 & 1.4 & 74.9 & 80.9 \\
\hline
\end{tabular}

Table 2. Correlations with temperature. Mortality is age-adjusted per 100,000. Temperature is in degrees Fahrenheit.

\begin{tabular}{lll}
\hline Variable & Correlation coefficient & p-value \\
\hline Year & 0.624 & $<0.001$ \\
All races mortality & -0.597 & $<0.0001$ \\
Black mortality & -0.619 & $<0.0001$ \\
White mortality & -0.589 & $<0.0001$ \\
\hline
\end{tabular}

\section{Discussion}

These results indicate that as temperature increased over the years, death rates unexpectedly tended to decrease. Limitations to the study are its (ecological) design, where individual exposures and outcomes are unknown. However, the design is also a strength in that the entire population of Texas is included. Further research for other states is indicated. Another limitation is that other factors that affect death rates were not included. However, even with the addition of these other factors, e.g., in a partial correlation analysis, the changing of these highly significant inverse correlations into direct correlations seems unlikely. Moreover, the dire predictions regarding global warming typically do not include attachment to the other factors. In other words, while smoking is a co-factor in death rates, claims of global warming+smoking are typically not made; the claim is usually made for global warming as a stand-alone (single) factor. So it was treated as such in the present study. Another factor not included in this study is the progress mankind makes over time that

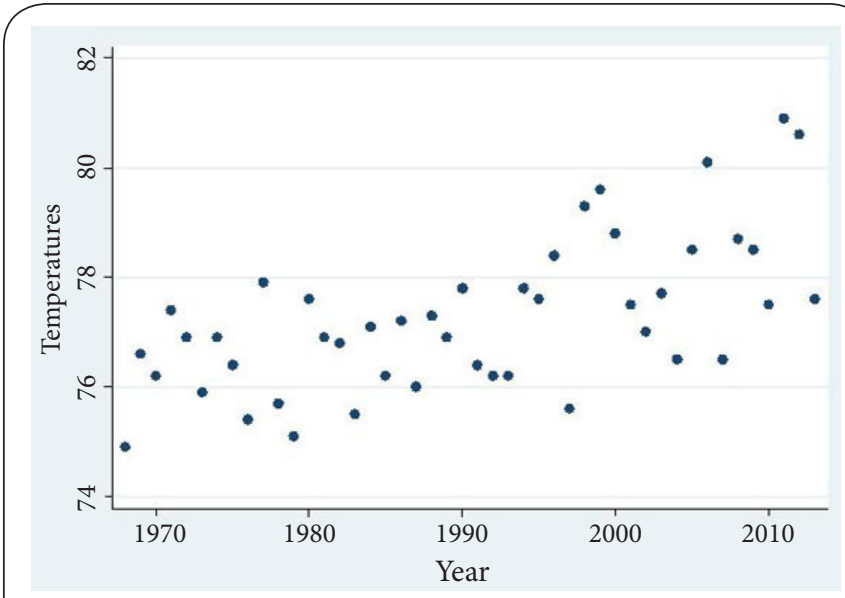

Figure 1. Scatter plot for temperature versus year, 1968-2013. Temperatures tended to increase over the years. However, Figures 2-4 indicate that increased temperatures tended to correlate with decreased death rates.

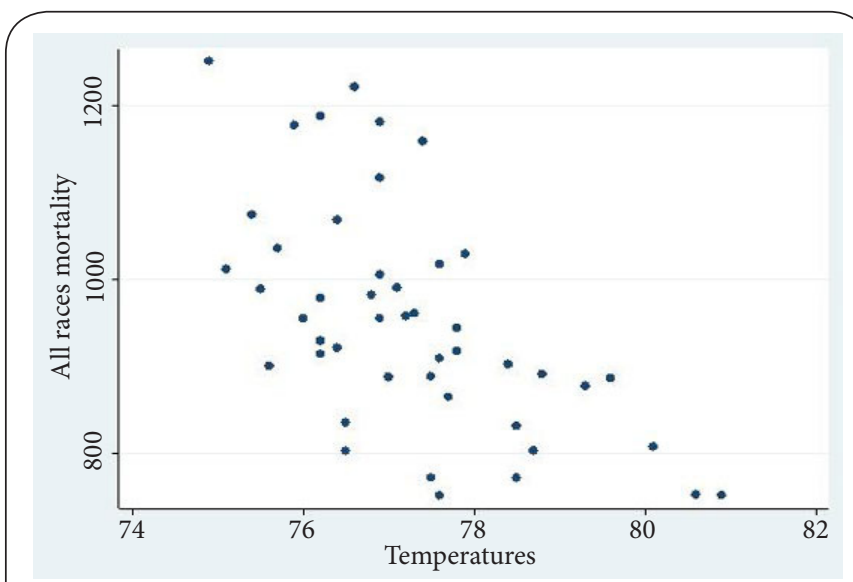

Figure 2. Scatter plot for temperatures versus all races mortality for 1968-2013. Death rates tended to decrease as temperature increased.

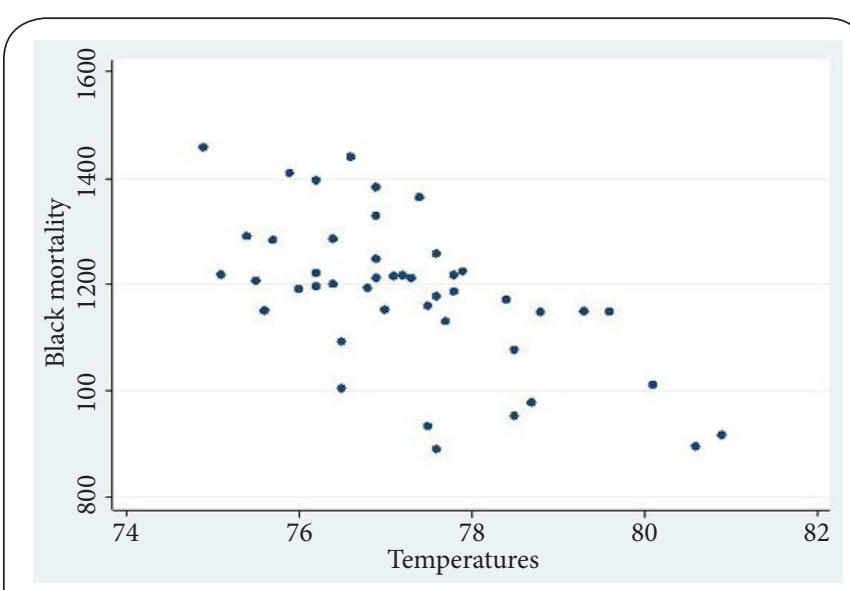

Figure 3. Scatter plot for temperatures versus black mortality for 1968-2013. Death rates tended to decrease as temperature increased. 


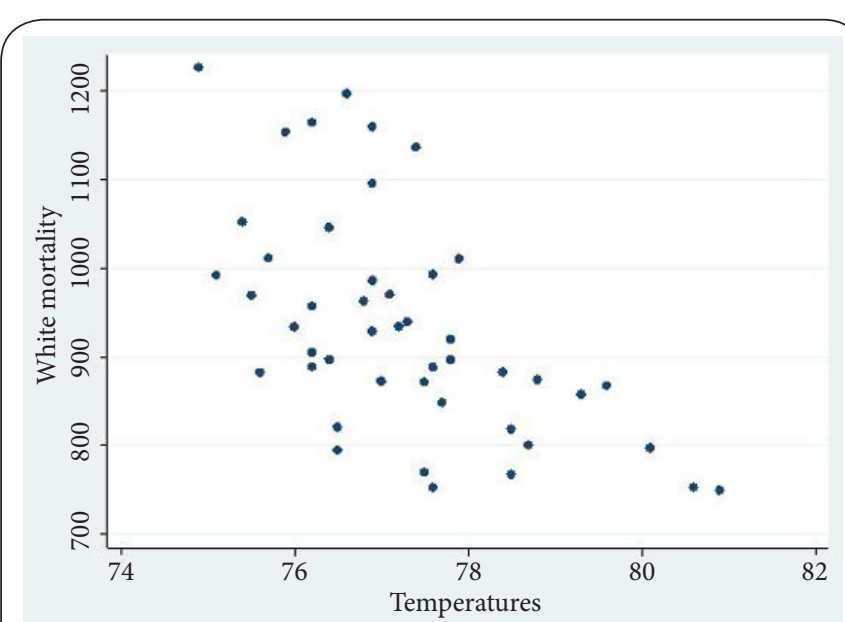

Figure 4. Scatter plot for temperatures versus white mortality for 1968-2013. Death rates tended to decrease as temperature increased.

likely prolongs lifespan. Here, it could be argued that warmer temperatures somehow may be associated with such progress since warmer temperatures have been linked with improved cognitive capacity [9]. Improved cognition in turn could lead to improved innovations that help to reduce death rates. Additionally, warmer temperatures may be a factor in driving down health care costs [10] which could improve access to health care. The improved access to health care could in turn be a factor in reducing death rates. These findings are similar to a recently published similar study for the continental U.S [11].

\section{Conclusion}

In this study, as temperatures increased, death rates tended to decrease. This result runs contrary to dire predictions of increased death rates due to global warming. Further research is indicated to verify these findings.

\section{Competing interests}

The author declares that he has no competing interests.

\section{Publication history}

Editor: Wen-Qing Li, National Cancer Institute, USA.

Received: 14-May-2015 Final Revised: 17-Jun-2015

Accepted: 20-Jun-2015 Published: 24-Jun-2015

\section{References}

1. University Corporation for Atmospheric Research. How much has the global temperature risen the the last $\mathbf{1 0 0}$ years? 2015. I Website

2. Gardner A. Global warming will cause rise in death rates. $A B C$ News. 2015. I Website

3. Scientific American. The Impact of Global Warming on Human Fatality Rates. 2015. | Website

4. Kalkstein LS and Greene JS. An evaluation of climate/mortality relationships in large U.S. cities and the possible impacts of a climate change. Environ Health Perspect. 1997; 105:84-93. | PubMed Abstract | PubMed Full Text

5. Hart J. Association between air temperature and deaths due to cancer and heart disease in Alabama. Applied Scientific Reports. 2015; 2:1. I Article

6. Hart J. Association between air temperature and cancer death rates in Florida: An ecological study. Dose Response. 2015; 13:1. | Article

7. Centers for Disease Control and Prevention (CDC Wonder). Compressed mortality. 2015. I Website

8. National Oceanic and Atmospheric Administration. Climate at a glance. 2015. | Website

9. Keller MC, Fredrickson BL, Ybarra O, Cote S, Johnson K, Mikels J, Conway $A$ and Wager T. A warm heart and a clear head. The contingent effects of weather on mood and cognition. Psychol Sci. 2005; 16:724-31. | Article | PubMed

10. Moore TG. Health and amenity effects of global warming. Economic Inquiry. 1998; 36:471-478. | Article

11. Hart J. Air Temperature and Death Rates in the Continental U.S.,19682013. Climate. 2015; 3:435-441. | Article

\section{Citation:}

Hart J. Air temperature and death rates in Texas, 1968-2013. Epidemiol Rep. 2015; 3:3. http://dx.doi.org/10.7243/2054-9911-3-3 